\title{
PRESENTACIÓN DEL LIBRO DE CARLOS PEÑA POR QUÉ IMPORTA LA FILOSOFÍA
}

\author{
Jorge Acevedo Guerra \\ Universidad de Chile \\ joaceved@gmail.com
}

$\overline{\mathrm{RA}}$ Nuestro amigo Carlos Peña comienza su obra Por qué importa la filosofía (2018) con un epígrafe debido a Hannah Arendt, en el que ella reconoce a Heidegger como un maestro con el que podríamos aprender a pensar. Así prepara la aparición de uno de los filósofos que toma especialmente en cuenta en su escrito.

Peña considera que la época moderna, que es la nuestra, es la era de la técnica, en el sentido que da Heidegger a esta expresión (2017a). Son los caracteres de la época técnica los que chocan frontalmente con el quehacer filosófico. Entre estas características podemos nombrar una central: erigir la eficacia productiva incondicionada como "valor" supremo. Ortega decía a sus oyentes en una conferencia que "el hecho decisivo de que vamos a partir y que es de sobra patente, consiste en que la producción es hoy la dimensión de la vida colectiva que se halla situada en primer término. No se trata de que sea la más estimada, sino que de hecho toda la vida colectiva funciona teniendo como eje de articulación la industria, el comercio y las actividades secundarias que ambas cosas traen consigo" (2010, p. 442). La producción sigue siendo en nuestros días el fenómeno central de la historia, al que, de algún modo, se supeditan los demás. La producción se mueve dentro de una legalidad en que hay normas que, ante todo y primordialmente, miden. El cálculo, en sentido amplio, rige la producción. Pero el rasero con que se controla la producción se ha hecho universal. No rige solo para la producción industrial y comercial. Ahora rige para todo.

Ortega, dejémoslo consignado, es uno de los autores a los que Peña recurre con más frecuencia, junto con Heidegger, Wittgenstein, Kant, Max Weber y algunos otros.

Así, entonces, las universidades, por ejemplo, son medidas con los parámetros con que se ha medido la productividad industrial y comercial. Deben optimizar su productividad en lo que se refiere a número de egresados, de titulados, de graduados, de proyectos de investigación, de publicaciones, etcétera, en lapsos que tienen que ser lo más breve posibles, con el mínimo gasto.

En cuanto a la filosofía, esos parámetros le son todavía más ajenos y externos. La filosofía, en efecto, no tiene por tarea central producir capital humano o capital humano avanzado, para usar la terminología economicista y técnica vigente en las agencias académicas. Su tarea esencial va por otro lado.

Se podría argumentar que la filosofía está al servicio de otras entidades que parecen muy útiles y serviciales y que, al subordinarse a ellas, la filosofía se contagia con esa utilidad y esa servidumbre y, finalmente, aparece también como sirviendo para 
algo y no como algo inútil. Es lo que hace, dice Peña, entre otros, Martha Nussbaum. El camino que toma Nussbaum es insuficiente, comenta el autor. "A fuerza de argumentar para salvar la utilidad de la filosofía, arriesga deformarla” (2018, p. 17).

Peña considera que hay que declarar paladinamente, desde el inicio, que la filosofía es un saber inútil, pero señorial, tomando en cuenta la postura de Heidegger (2018, p. 29). Este último anota en unos "Suplementos" de sus Cuadernos de trabajo: "Pensar es [...] la pasión por lo inútil" (2017b, p. 226). Por cierto, en este contexto, inútil no significa carente de importancia, sino todo lo contrario. En este caso, lo inútil apunta hacia lo más importante. (En estos "Suplementos" hay una de las pocas referencias a Wittgenstein).

Insiste en lo mismo con Kant, quien piensa que en la Universidad debe haber una facultad-la Facultad de Filosofía- "cuyo quehacer sea, por decirlo así, inútil en la medida en que no está al servicio de ningún designio más que el sometimiento a la mera racionalidad" (2018, pp. 182 ss.).

Plantea Peña que "es propio de lo humano preguntarse por el ser y al hacerlo, al ensayar una comprensión de ese problema, configurarse a sí mismo. [...]. El ser humano sería ontológico en el sentido que es el problema del ser, las respuestas que ensaya y la capacidad de ensayar esas respuestas, lo que lo constituye en lo que tiene de más propio. Detenerse en ese proyecto ayuda a entender la radicalidad que puede alcanzar la filosofía" (2018, p. 43).

Ya empezamos a vislumbrar la importancia de la filosofía. Su radicalidad y aquello de que trata hacen de ella un modo de pensar único, insustituible e insoslayable.

Por cierto, Peña deja en claro que habérselas con el ser no implica desatender $\mathrm{y}$ desentenderse del hombre. Ya lo ha establecido: en el pensar el ser -o en el ensayo de pensarlo- se cultiva lo más propio del hombre. Pero, además, trae a colación un texto de Heidegger que sería menester tener presente. Este: "La pregunta por el ser y por sus transformaciones y posibilidades es, en su núcleo, la pregunta correctamente entendida por el hombre. Frente a la permanencia de las galaxias del cosmos, la existencia humana y su historia es, sin duda, fugacísima, solo un "instante", pero la fugacidad es, asimismo, el modo supremo del ser cuando se convierte en el existir desde la libertad y para la libertad. ¡La altura del ser y de su modo de ser no depende de la duración!” (2009, p. 29).

El mundo actual, el mundo moderno o técnico, es meditado por Heidegger. Peña tiene en cuenta esta meditación para hacer sus cuestionamientos. Tal mundo no se reduce, ni mucho menos, a los artefactos técnicos: satélites de comunicación, observatorios astronómicos. Tampoco se reduce a los dispositivos tecnológicos: el Estado moderno, las redes informáticas, la industria educativa, del entretenimiento, de la alimentación, turística (Heidegger 2008). El mundo no es algo particular de que me ocupe, una cosa, 
un ente intramundano, un objeto. Como señala Ortega, mundo no es, tampoco, la suma de las cosas, sino el "horizonte" de totalidad sobre las cosas y distinto de ellas (2006a, p. 128, en nota). Mundo "es la arquitectura del contorno, la unidad de lo que nos rodea, el programa último de lo que es posible e imposible en la vida" (2004, p. 809).

Recordemos con Peña que para Heidegger "un mundo es algo inobjetivo que le da sentido a las cosas, [es] ese trasfondo inexplicable, oculto, soterrado que confiere la manera de ser a nuestras prácticas" (2018, p. 96).

Pues bien, el mundo técnico -el actual- es aquel en que prima el asumir los entes como stocks, reservas, fondos, subsistencias puestas "a disposición de la voluntad de alguien". A la par, el hombre es comprendido y asumido ante todo como material humano, como recurso humano (Heidegger 2005b, p. 215). Ese sería el resultado de una particular "comprensión del ser". Pero esa comprensión del ser no es el fruto de un acto deliberado, o de una decisión ideológica, sino que es el producto de un mundo ya constituido y si la filosofía no puede cambiarlo, sí, al menos puede pensarlo y "mostrar su contingencia" (2018, p. 97).

En "Ciencia y meditación”, Heidegger destaca "una frase, citada a menudo, de Max Planck [...]: "Es real lo que se deja medir". Esto significa: lo que decide qué debe valer en la ciencia, en este caso en la Física, como conocimiento seguro, es la mensurabilidad" (2017a, p. 105). En nuestro mundo técnico esta tesis, válida en principio para las ciencias físico-matemáticas, tiende a hacerse ilimitada, de tal modo que transforma lo distinto en algo homogéneo, nivelando y aplanando todo, uniformizando y formateando cuanto hay. Lo que no se deja medir no es real, es decir, es una nada y, por tanto, cae fuera de una consideración seria, queda al margen del núcleo de la vida, desplomándose en lo irreal y fantasmagórico.

Ni la filosofía, ni los mundos ingrávidos y gentiles, como pompas de jabón, que la poesía desoculta y que Antonio Machado amaba, tienen cabida en la era atómica. A no ser que se los ubique en el sector "cultura" de una colectividad, sector que, guiado por una "política cultural” (Heidegger 2005a, pp. 63 s.), los haga ingresar en el ámbito de los ajetreos culturales: fructíferos algunos, infecundos otros.

No obstante, vemos, a través de la revisión de la obra que comentamos, que a pesar del desdén y de la hostilidad del mundo de la técnica moderna hacia la filosofía, esta se autoafirma. Contra viento y marea, perdura. Al menos, hasta ahora.

En el "Anejo" de sus Apuntes sobre el pensamiento, Ortega plantea que la justificación de la filosofía es su primer principio (2006b, p. 26). Carlos Peña se ha hecho cargo de este primer principio de manera admirable, mostrando, desde diversas perspectivas, por qué importa la filosofía. No es nada de fácil transitar desde una postura que asume de partida y sin reservas la inutilidad de la filosofía hacia una fundada mostración de su importancia. Nuestro autor lo ha hecho con lucidez y perspicacia. Reciba nuestras más sinceras y profundas felicitaciones. 


\section{Referencias bibliográficas}

Heidegger, Martin (2017a), Filosofía, ciencia y técnica. Trad. de Francisco Soler Grima y María Teresa Poupin Oissel. Santiago de Chile: Ed. Universitaria. (2017b), "Reflexiones VII-XI. Cuadernos negros (1938-1939)". Trad. de Alberto Ciria Cosculluela. Madrid: Ed. Trotta.

(2009), Principios metafísicos de la lógica. Trad. de Juan José García Norro. Madrid: Ed. Síntesis.

(2008), Estancias. Trad. de Isidoro Reguera. Valencia: Ed. Pre-Textos. Nota a la edición de Luise Michaelsen. Con tres acuarelas de Elfriede Heidegger.

(2005a), "La época de la imagen del mundo". Caminos de bosque. Trad. de Helena Cortés y Arturo Leyte. Madrid: Ed. Alianza. (2005b), “Para qué poetas?”. Caminos de bosque, ed. cit.

Ortega y Gasset, José (2010), "El fondo social del management europeo". Obras Completas, vol. X. Madrid: Ed. Taurus/Fundación José Ortega y Gasset.

(2006a). Pidiendo un Goethe desde dentro. Carta a un alemán. Obras Completas, vol. V, ed. cit.

(2006b), Apuntes sobre el pensamiento, su teúrgia y su demiúrgia. Obras Completas, vol. VI, ed. cit.

(2004). "Revés del almanaque". El Espectador VIII. Obras Completas, vol. II, ed. cit.

Peña, Carlos (2018), Por qué importa la filosofía. Santiago de Chile: Ed. Taurus. 